\title{
Effect of Compositional Variation Induced by EBM Processing on Deformation Behavior and Phase Stability of Austenitic Cr-Mn-Ni TRIP Steel
}

\author{
J. GÜNTHER, ${ }^{1}$ R. LEHNERT, ${ }^{2}$ R. WAGNER,${ }^{2}$ C. BURKHARDT, ${ }^{2}$ \\ M. WENDLER, ${ }^{3}$ O. VOLKOVA, ${ }^{3}$ H. BIERMANN, ${ }^{2}$ \\ and T. NIENDORF (iD)
}

1.-Institute of Materials Engineering, Universität Kassel, Mönchebergstraße 3, 34125 Kassel, Germany. 2.-Institute of Materials Engineering, Technische Universität Bergakademie Freiberg, Gustav-Zeuner-Straße 5, 09599 Freiberg, Germany. 3.-Institute of Iron and Steel Technology, Technische Universität Bergakademie Freiberg, Leipziger Straße 34, 09599 Freiberg, Germany. 4.—e-mail: niendorf@uni-kassel.de

Electron beam melting (EBM) is an established powder bed-based additive manufacturing process for the fabrication of complex-shaped metallic components. For metastable austenitic Cr-Mn-Ni TRIP steel, the formation of a homogeneous fine-grained microstructure and outstanding damage tolerance have been reported. However, depending on the process parameters, a certain fraction of Mn evaporates. This can have a significant impact on deformation mechanisms as well as kinetics, as was previously shown for as-cast material. Production of chemically graded and, thus, mechanically tailored parts can allow for further advances in terms of freedom of design. The current study presents results on the characterization of the deformation and strain-hardening behavior of chemically tailored Cr-Mn-Ni TRIP steel processed by EBM. Specimens were manufactured with distinct scan strategies, resulting in varying Mn contents, and subsequently tensile tested. Microstructure evolution has been thoroughly examined. Starting from one initial powder, an appropriate scan strategy can be applied to purposefully evaporate Mn and, therefore, adjust strain hardening as well as martensite formation kinetics and ultimate tensile strength.

\section{INTRODUCTION}

Electron beam melting (EBM) is an additive manufacturing (AM) technique applicable for the production of complex designed metallic components solely based on the specifications given by a computer-aided design model. Similar to laser powder bed fusion (L-PBF), EBM is a powder bed-based process implementing consecutive local melting of thin powder layers on top of each other. ${ }^{1-4}$ The advantages in terms of efficient production and unprecedented freedom of design resulting from this tool-free and flexible production technique have recently gained increased academic interest. Furthermore, applications in various fields such as the aerospace and biomedical industries due to lightweight design, biocompatibility and cost reduction potential have been reported. ${ }^{5-9}$

Upon adequate post-treatment, AM-processed materials are usually characterized by good mechanical properties similar or occasionally even superior to conventionally manufactured counterparts. However, the final performance is strongly affected by various factors that are difficult to control. Firstly, the static and especially cyclic mechanical behavior of AM parts are significantly influenced by process-induced voids and cavities. ${ }^{10-14}$ In previous studies on the fatigue behavior of machined L-PBF- and EBM-manufactured Ti$6 \mathrm{Al}-4 \mathrm{~V}$ specimens, it has been demonstrated that 
the fatigue performance of stress-relieved as well as as-built conditions, i.e., without any further postprocessing, is significantly impaired in comparison to the hot isostatic-pressed (HIP) condition. The HIP-treated material can be considered defectfree, ${ }^{11}$ as remaining defects are of subcritical size regarding crack initiation. It was shown that in nonHIP-processed conditions, fatigue cracks are initiated either on gas porosity, presumably stemming from the initial gas atomized powder, or the socalled lack-of-fusion defects that originate from insufficient local energy input. ${ }^{11,15}$ Another factor determining the performance of AM products can be the occurrence of strong crystallographic textures. Solidification with a preferred $\langle 001\rangle$ orientation with respect to build direction (BD), as well as epitaxial growth leading to the formation of elongated grains over several layers (cf. Ref. 16), have been reported many times. This microstructure evolution has been reported for various alloys, e.g., Ni-based superalloy IN 718, ${ }^{17-22}$ aluminum alloys, ${ }^{23}$ the primary bcc $\beta$-phase in Ti-6Al-4V, ${ }^{24,25}$ and several austenitic steels processed by L-PBF 26 and EBM. ${ }^{27}$ Evolution is mainly attributed to the principal heat flux alongside BD and the favorable $\langle 100\rangle$ growth direction in cubic crystal systems, due to an anisotropy in the solid-liquid interface energy. This strong texture yields a significant orientationdependent elastic behavior as well as plastic deformation anisotropy. The shear stresses on various dislocation slip systems and the associated activation of complex deformation mechanisms, like strain-induced twinning and martensitic transformation, are affected simultaneously. ${ }^{28-32}$ Moreover, the fatigue behavior and cyclic stress-strain response can be affected, as has been shown in the low-cycle fatigue regime for an IN 718 alloy. ${ }^{33,34}$

In a first study reporting on EBM processing of a metastable austenitic $\mathrm{Cr}-\mathrm{Mn}-\mathrm{Ni}$ steel, the material has been introduced as a novel promising alloy design for layer-wise AM. It was shown that the material in its as-built condition, i.e., without the necessity of elaborate post-processing, is capable of addressing the aforementioned major current challenges in powder bed-based AM. ${ }^{35}$ Firstly, independent of the applied process parameters, the steel is characterized by a homogeneous microstructure with a remarkably weak texture, i.e., approximately 1.6 and 1.4 multiples of uniform distribution (MUD) as determined by electron back-scatter diffraction (EBSD) and x-ray diffraction (XRD). Moreover, relatively fine grains prevail with a mean areaweighted grain size of approximately $20 \mu \mathrm{m}$, as derived from EBSD data (cf. Ref. 35). This microstructure evolution was attributed to the characteristic temperature-dependent phase fractions, as calculated for a Cr-Mn-Ni $16-X-6$ alloy and verified by differential thermal analysis. The special feature of this alloy system is a largely extended $b c c+f c c$ phase field at above approximately $1200^{\circ} \mathrm{C}$. Considering the complex thermal history of an arbitrary material volume element caused by the successive melting of powder layers on top of each other, and the overlap of individual melt scan tracks in a single layer, the multiple and repetitive $f c c \rightarrow$ $b c c+f c c$, and vice versa, phase transformations were assumed to have a grain refining effect, and to be eventually responsible for the suppression of formation of strong texture. Moreover, the alloy is characterized by a relatively low stacking fault energy (SFE) and, thus, shows transformationinduced plasticity (TRIP) effect, i.e., it undergoes a martensitic transformation induced by deformation (cf. Ref. 36, 37). This phenomenon is based on the interaction of partial dislocations, the formation and expansion of stacking faults (SF) on the $\{111\}$ planes, and their arrangement in the austenite matrix. The $\alpha^{\prime}$ martensite usually nucleates in intermediate hexagonal domains, often referred to as $\varepsilon$ martensite, and their intersections, according to the $\gamma \rightarrow(\mathrm{SF} ; \varepsilon) \rightarrow \alpha^{\prime}$ path. ${ }^{29,38-44}$ This transformation yields a high strain-hardening rate based on the dynamic Hall-Petch effect, delayed necking, and an extraordinary damage tolerance. It has been demonstrated that the material still exhibits excellent mechanical properties even in the presence of large process-induced defects, i.e., lack-of-fusion defects (cf. Ref. 35, 41). This remarkable defect tolerance has not only been comprehensively shown for static, but also for cyclic mechanical response in low-cycle fatigue tests by Droste et al. ${ }^{45}$ The combination of the exceptional microstructure evolution and the noticeably diminished susceptibility of material properties to common process-inherent inhomogeneities make this alloy well suited for powder bed fusion AM processes.

Furthermore, it has been shown that the alloying element $\mathrm{Mn}$ is prone to vaporization due to its high vapor pressure, i.e., depending on the process parameters and the volume energy, $E_{\mathrm{vol}}$, the fraction can be diminished from more than 6 wt. $\% \mathrm{Mn}$ in the precursor powder to less than 4 wt.\%. ${ }^{35,46,47}$ Wendler et al. ${ }^{48,49}$ demonstrated for different $14 \mathrm{Cr}-\mathrm{XMn}-6 \mathrm{Ni}-0.1 \mathrm{~N}$ cast alloys that the $\mathrm{Mn}$ content not only has an effect on the stability of the respective phases but also strongly affects the SFE and, thus, the deformation mechanisms and kinetics, resulting in different stress-strain responses, tensile strengths, and total elongations.

Despite compositional variations upon AM (e.g., induced by the evaporation of $\mathrm{Al}$ and $\mathrm{Mg}$ ) usually being unfavorable, as discussed in various studies, ${ }^{5-53}$ the objective of the present work is the investigation of the impact of EBM processing parameters on the loss of $\mathrm{Mn}$, the resulting mechanical response and phase evolution upon tensile testing. The results allow to evaluate if it is possible to manufacture specimens with locally differing properties by EBM from one initial pre-alloyed precursor powder material through a suitable setting of process parameters in order to realize functionally graded parts by chemical gradation. It 
will be shown that the phase transformation kinetics, as well as the prevailing microstructural constituents upon tensile deformation, can be varied, as less Mn yields higher bcc $\alpha^{\prime}$ and lower hexagonal $\varepsilon$ martensite fractions. This novel approach has two main advantages compared to alternative methods: (1) the powder can be reused without any elaborate recycling steps, i.e., no separation of different powder feedstocks is necessary as in the case of approaches using different ingot powders; ${ }^{54}$ and (2) the specimens are characterized by almost isotropic properties. The latter aspect contributes the major difference to an alternative approach only using a single ingot powder, i.e., the fabrication of specimens with diverging behavior induced by direct microstructure design, i.e., a process-induced change in grain morphology from equiaxed to columnar grains, inevitably yielding a certain degree of mechanical anisotropy. In contrast, the presented Cr-Mn-Ni alloy develops a weak-textured and relatively fine-grained microstructure independent of the applied EBM process parameters.

\section{MATERIALS AND METHODS}

The precursor Cr-Mn-Ni TRIP steel powder has been gas-atomized by the electrode induction-melting gas atomization technique (TLS Technik, Spezialpulver, Germany). The powder has a nominal composition of 15.8 wt.\% $\mathrm{Cr}, 6.4$ wt.\% $\mathrm{Mn}$ and 5.9 wt. $\% \mathrm{Ni}$ (balance $\mathrm{Fe}$ ), and mean particle sizes of $d_{50}=72.5 \mu \mathrm{m}$ and $d_{90}=118.8 \mu \mathrm{m}$ (for further details, see Ref. 35, 45). The material has been processed by EBM using an ARCAM A2X machine (GE Additive, formerly ARCAM, Sweden). Table I summarizes the applied process parameters, resulting energy densities $E_{\mathrm{vol}}$ as well as the Mn content and the porosity of the fabricated tensile specimens (as determined by energy-dispersive $\mathrm{x}$-ray spectroscopy (EDS)). The energy density, the energy per volume unit, is calculated according to $E_{\mathrm{vol}}=$ $\left(I_{\mathrm{B}} \times U_{\mathrm{a}}\right) /\left(v_{\mathrm{s}} \times l \times t\right)$ with $I_{\mathrm{B}}$ representing the beam current, $v_{\mathrm{s}}$ the scan speed and $l$ the hatch, i.e., the distance between adjacent scan tracks. The machine operates at an acceleration voltage, $U_{\mathrm{a}}$, of $60 \mathrm{kV}$ and the layer thickness, $t$, has been set to $50 \mu \mathrm{m}$. A meander-shaped scan strategy has been applied and the scan direction has been rotated about $90^{\circ}$ each layer.
Prior to fetching the powder for the first layer, the substrate plate made of AISI 304 stainless steel has been heated to $850^{\circ} \mathrm{C}$. Additionally, prior to melting of the contour of the part, each powder layer has been preheated using a highly defocused electron beam, at a beam current of $17.5 \mathrm{~mA}$, a line offset of $1 \mathrm{~mm}$, and a scan speed of $12,000 \mathrm{mms}^{-1}$.

Microstructure investigations have been conducted using a field emission-gun scanning electron microscope (SEM) MIRA 3 (Tescan, Czech Republic) equipped with secondary electron (SE), back-scattered electron (BSE), electron backscatter diffraction (EBSD) and EDS detectors. For analysis, the specimens were ground, polished to the grit size of $1 \mu \mathrm{m}$, and subsequently vibration-polished to obtain a reasonable surface quality (cf. Ref. 55). The aspect ratio of the grain (size) was acquired from the EBSD software. The data have been analyzed using OIM Analysis $^{\mathrm{TM}} 6$ software (EDAX, USA). The program approximates grains by fitting, using an ellipse and calculating the ratio of the length of minor and major axes. Individual grains were defined by a misorientation angle of $15^{\circ}$.

Tensile tests have been performed using a miniature load frame (Kammrath \& Weiß, Germany) equipped with a $10 \mathrm{kN}$ load cell at a strain rate of $1.25 \times 10^{-3} \mathrm{~s}^{-1}$. The tensile specimens with the geometry given in the inset of Fig. $2 \mathrm{a}$ have been machined from EBM-fabricated cuboids with a cross-section of $20 \times 20 \mathrm{~mm}^{2}$ and a height of $40 \mathrm{~mm}$ by electro-discharge machining. The strain has been logged using a digital video-extensometer (Veddac Strain; Chemnitzer Werkstoffmechanik, Germany). True stress, $\sigma_{\text {true, }}$ and true strain, $\varepsilon_{\text {true }}$, have been calculated from the engineering stress, $\sigma_{\text {eng, }}$, and engineering strain, $\varepsilon_{\text {eng }}$, by $\sigma_{\text {true }}=\sigma_{\text {eng }} \times\left(1+\varepsilon_{\text {eng }}\right)$ and $\varepsilon_{\text {true }}=\ln \left(1+\varepsilon_{\text {eng }}\right)$. The value for uniform elongation, i.e., the beginning of necking, has been determined by applying Considère's criterion, $\mathrm{d} \sigma_{\text {true }} / \mathrm{d} \varepsilon_{\text {true }}=\sigma_{\text {true }}$.

For phase analysis, XRD measurements were performed using a Seifert URD6 (FPM Holding, Germany) with $\mathrm{CoK} \alpha$ radiation. Specimens have been investigated in as-built condition and upon deformation to uniform elongation, respectively, corresponding to the conditions probed by EBSD. Quantitative phase analysis from XRD data has been performed by Rietveld refinement using the TOPAS software package (Bruker, USA).

Table I. Overview of investigated batches, applied process parameters, resulting energy density, Mn content and porosity

\begin{tabular}{|c|c|c|c|c|c|c|}
\hline Batch & Beam current (mA) & Scan speed $\left(\mathrm{mms}^{-1}\right)$ & Hatch $(\mu \mathrm{m})$ & $E_{\mathrm{vol}}\left(\mathrm{Jmm}^{-3}\right)$ & Mn (wt.\%) & Porosity (\%) \\
\hline I & 7.5 & 4100 & 75 & 29.3 & 6.2 & 0.91 \\
\hline II & 7.5 & 3300 & 75 & 36.4 & 5.6 & 0.43 \\
\hline III & 7.5 & 1600 & 90 & 62.5 & 4.9 & 0.39 \\
\hline IV & 7.5 & 2100 & 75 & 57.1 & 4.3 & 0.36 \\
\hline $\mathrm{V}$ & 7.5 & 1700 & 75 & 70.6 & 3.3 & 0.41 \\
\hline
\end{tabular}


The relative density and porosity, respectively, of the specimens have been determined according to Archimedes' principle, referring to a presumed theoretical bulk density of $7.86 \mathrm{gcm}^{-3}$. The stacking fault energies (SFE) and martensite start temperatures $\left(\mathrm{M}_{\mathrm{S}}\right)$ of the specimens were estimated using empirical equations proposed by Dai et al. ${ }^{56}$ and Jahn et al. ${ }^{57}$ respectively. For calculation, in both cases it has been presumed that the variation of $\mathrm{Mn}$ is compensated by the $\mathrm{Fe}$ content and that the concentration of other alloying elements remains constant.

\section{RESULTS}

Figure 1a and c-f shows EBSD micrographs of the gauge length of the tensile specimens (geometry shown in inset of Fig. 2a) of all the tested batches in as-built condition. As a representative example (Fig. 1b) the texture intensity plot and corresponding scale bar for batch $\mathrm{I}$ is given, indicating a weak texture (1.84 MUD, [001] refers to BD). The corresponding area-weighted grain size (cf. Ref. 45) as derived from the EBSD data is $22 \mu \mathrm{m}$ with an average aspect ratio of 0.4 , the long axis being almost parallel to the build direction. All batches are almost fully austenitic in as-built condition, as later confirmed by XRD analysis.

The resulting Mn contents as determined by EDS from the tested batches are listed in Table I. For the specimens melted with a hatch of $75 \mu \mathrm{m}$, a clear trend towards more pronounced Mn loss can be deduced with decreasing scan speed, $v_{\mathrm{s}}$. Thus, an increase of the volume energy, $E_{\mathrm{vol}}$, as well as the line energy, $E_{1}$, decreases the $\mathrm{Mn}$ content of the alloy; e.g., the initial Mn content in the precursor powder is reduced from 6.4 wt.\% to $6.2 \mathrm{wt} \%$ for batch I melted with a scan speed of $4100 \mathrm{mms}^{-1}$, whereas the reduction of the scan speed to $1700 \mathrm{mms}^{-1}$ in batch V yields a significant reduction of the Mn content to approximately $3.3 \mathrm{wt} . \%$. The line energy is defined as the energy input per single scan track and calculated by $E_{\mathrm{l}}=I_{\mathrm{B}} \times U_{\mathrm{a}} \times v_{\mathrm{s}}^{-1}$. However, $E_{\mathrm{vol}}$ and $E_{1}$ cannot be considered as isolated values determining the vaporization of $\mathrm{Mn}$, as can be seen for batch III, which is characterized by a nominal higher $E_{\mathrm{vol}}$ but also higher Mn content as compared to batch IV. Correlations are further detailed in the "Discussion" section.

Figure 2a displays the engineering stress versus engineering strain curves for all batches as obtained by the tensile tests. Figure $2 \mathrm{~b}$ shows the calculated true stress versus true strain curves as well as the corresponding strain-hardening curves, defined as the derivative $\mathrm{d} \sigma_{\text {true }} / \mathrm{d} \varepsilon_{\text {true }}$. As can be seen, batch I is characterized by the lowest ultimate tensile strength (UTS) and lowest elongation to fracture $\left(\varepsilon_{\mathrm{f}}\right)$, as well as minor strain hardening. However, it has to be emphasized that the stress-strain behavior is significantly superimposed by large process- induced defects, as will be presented later. Batches II, III and IV are characterized by almost similar UTS and $\varepsilon_{f}$, as can be seen in Fig. 2a, although the specimens reveal different strain hardening, i.e., batch II with higher Mn content shows less pronounced hardening. The highest UTS (over $900 \mathrm{MPa}$; cf. Table II) and strain hardening with concomitantly slightly decreased $\varepsilon_{\mathrm{f}}$ can be seen for batch V, i.e., the specimens with the lowest $\mathrm{Mn}$ content.

Figure 3 shows image quality (IQ) (also referred to as band contrast) maps obtained by EBSD analysis of specimens of batches (a) I, (c) III and (e) V, as well as the associated phase maps in (b), (d) and (f), respectively, upon tensile deformation to uniform elongation. It can be seen that a high density of deformation bands forms on numerous active slip systems, and that, with increasing $E_{\mathrm{vol}}$, i.e., decreasing Mn content, the fractions of fcc $\gamma$ and hexagonal $\varepsilon$ martensite decrease, while bcc $\alpha^{\prime}$ martensite becomes the dominating phase, indicating a pronounced TRIP effect.

Moreover, Fig. $3 \mathrm{~g}$ and $\mathrm{h}$ shows the microstructure of batch III in SEM-BSE contrast at different magnifications. The micrographs display a highly deformed microstructure, highlighting the underlying deformation characteristics of this particular alloy. Deformation is mainly based on the formation and interaction of partial dislocations, their arrangement in deformation bands, the formation of hexagonal $\varepsilon$ martensite domains, and the transformation to $\alpha^{\prime}$ martensite that acts as an effective barrier to dislocation motion, yielding high strain hardening (cf. Ref. 35, 41, 42).

Figure 4 depicts the XRD diffraction patterns for batches I, II, IV and V in (a) as-built condition and (b) upon tensile deformation to uniform elongation. Findings are in line with the EBSD measurements given in Fig. 3.

In the as-built condition, fcc $\gamma$ is generally the dominant phase as already shown by the EBSD results. However, XRD analysis additionally reveals small $\varepsilon$ fractions in the as-built condition of batches I and II (cf. Fig. 4a), which can be quantified to $(6 \pm 1)$ and $(9 \pm 1)$ vol.\% using Rietveld refinement. Upon deformation, the $\varepsilon$ martensite fraction in these batches evolves differently, i.e., to $(16 \pm 2)$ and $(3 \pm 1)$ vol.\%. The decrease in absolute value in batch II has to be rationalized based on the concomitant evolution of the bcc $\alpha^{\prime}$ phase. In batches IV and $\mathrm{V}$, no $\varepsilon$ martensite was detected in the deformed condition. The fraction of the bcc $\alpha^{\prime}$ phase in batch I upon tensile deformation according to XRD measurements is $(51 \pm 4)$ vol.\%. The absolute value is significantly higher in batches II and IV with $(89 \pm 3)$ vol.\% and $(84 \pm 2)$ vol.\%, respectively, and highest in batch $\mathrm{V}$ with $(92 \pm 3)$ vol.\%. Clearly, the specimen with lowest Mn content is almost fully martensitic upon deformation to uniform elongation (cf. Table II). 

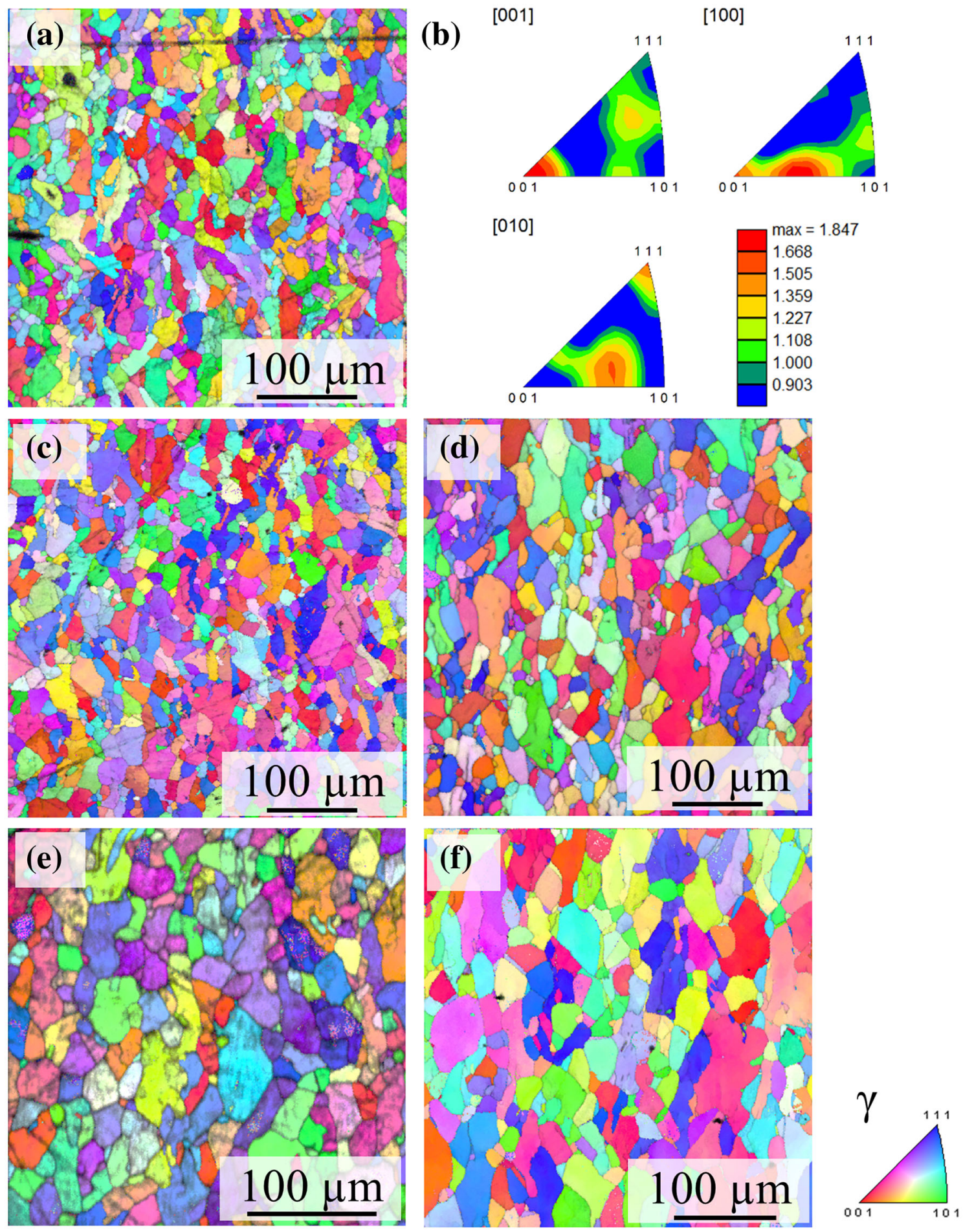

Fig. 1. EBSD micrographs (inverse pole figures, superimposed Image Quality, color coding given for fcc $\gamma$ phase) for as-built condition of tensile specimens (a) I, (c) II, (d) III, (e) IV and (f) V; (b) texture intensity plot and corresponding scale bar for specimen I, [001] direction refers to BD.

Figure 5 shows representative fracture surfaces of specimens of batches I, II and V, as well as magnified views of dominant defects. It can be seen that batch I, i.e., the specimen melted with the highest scan speed and lowest $E_{\mathrm{vol}}$, is characterized by large areas with virtually unmelted powder particles. These inhomogeneities, usually referred to as lack-of-fusion defects (LoF, cf. Ref. 15), have diameters of up to approximately $300 \mu \mathrm{m}$ (cf. Fig. 5b) in this condition. Relatively large LoF defects characterized by an irregular shape are also observed in batch II; however, at higher values of $E_{\mathrm{vol}}$, no unmelted residual powder remains present (see Fig. 5c and d). Upon further increase of $E_{\mathrm{vol}}$ no 
(a)

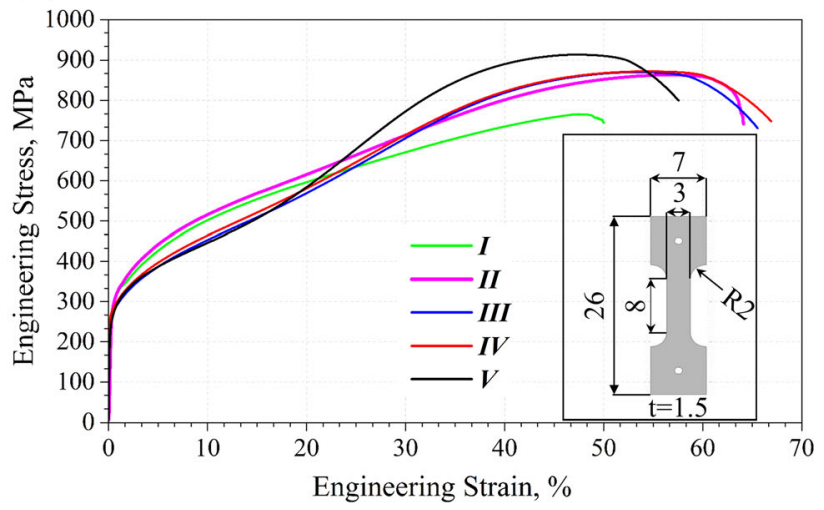

(b)

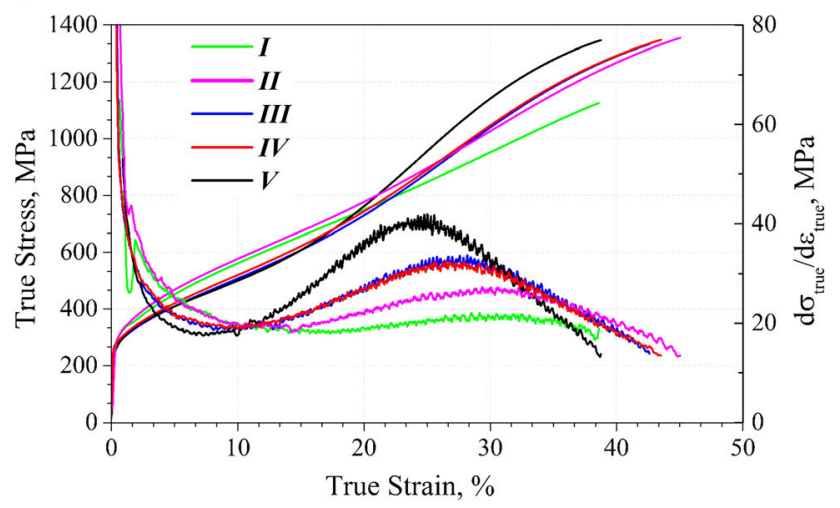

Fig. 2. (a) Engineering stress versus engineering strain curves for all tested batches, (b) true stress versus true strain curves and strain hardening curves; the inset in (a) depicts the geometry of the tensile specimens.

Table II. Summary of stacking fault energy $(S F E), M_{S}$ temperature, ultimate tensile strength (UTS), total elongation $\varepsilon_{t}$ and martensite fractions upon deformation to uniform elongation for batches I, II, IV and V

\begin{tabular}{|c|c|c|c|c|c|}
\hline Batch & $\underset{\left(\mathbf{m J m}^{-2}\right)}{\mathbf{S F E}}$ & $\underset{\left({ }^{\circ} \mathbf{C}\right)}{\mathbf{M}_{\mathbf{S}}}$ & UTS (MPa) & $\varepsilon_{\mathrm{t}}(\%)$ & $\begin{array}{c}\text { Martensite fraction upon tensile } \\
\text { deformation (vol.\%) }\end{array}$ \\
\hline I & 12.15 & -24 & $\begin{array}{c}750 \\
(750 \pm 15)^{*}\end{array}$ & $\begin{array}{c}46 \\
(46 \pm 4)^{*}\end{array}$ & $\begin{array}{l}(16 \pm 2) \varepsilon \\
(54 \pm 4) \alpha^{\prime}\end{array}$ \\
\hline II & 12.27 & -18 & $\begin{array}{c}856 \\
(856 \pm 7)^{*}\end{array}$ & $\begin{array}{c}67 \\
(67 \pm 3)^{*}\end{array}$ & $\begin{array}{l}(3 \pm 1) \varepsilon \\
(89 \pm 3) \alpha^{\prime}\end{array}$ \\
\hline IV & 12.67 & -3 & 872 & 67 & $(84 \pm 2) \alpha^{\prime}$ \\
\hline V & 13.10 & 11 & 914 & 57.5 & $(92 \pm 3) \alpha^{\prime}$ \\
\hline
\end{tabular}

UTS and $\varepsilon_{\mathrm{t}}$ values of batches I and II correspond to mean values of multiple tests. Values marked with asterisks indicate the defined ranges of uncertainty for the mechanical property data. As only single specimens of batches IV and V have been tested to failure, levels of uncertainty are not provided.

defects remain visible, i.e., $E_{\mathrm{vol}}$ was sufficient for full consolidation (cf. Fig. 5f); instead, the prevalent defects are more spherical and presumable induced by residual gas entrapped in the precursor powder as a remnant from the gas-atomization process and keyholing, respectively. ${ }^{58-60}$ This is also supported by the relative densities determined, presented in Table I as characterized by Archimedes' principle. Accordingly, batch I is characterized by the highest porosity. An increase in $E_{\mathrm{vol}}$ reduces the porosity; however, the relative density for batch $\mathrm{V}$ also does not exceed a value of about $99.6 \%$.

\section{DISCUSSION}

Powder bed-based AM technologies, i.e., EBM, as well as L-PBF, allow for the fabrication of components with tailored and spatially varying mechanical properties. This can comprise geometrical grading, e.g., for a modification of the elastic modulus for biomedical applications, ${ }^{61-64}$ as well as modification of microstructure and texture evolution by an appropriate adaption of process parameters. ${ }^{17-19,23,65-67}$ Moreover, it is basically possible to adjust material deformation behavior by incorporating compositional variations. The principle of chemical grading has been implemented many times by means of laser metal deposition (also referred to as direct energy deposition), i.e., laserassisted freeform fabrication, and has been reported for various material combinations. ${ }^{68-73}$ Similar results for powder bed-based AM have been obtained by Hengsbach et al. and Liu et al. through L-PBF processing of dissimilar material combinations, i.e., AISI 316L with $\mathrm{H}_{13} 3^{54}$ and $316 \mathrm{~L}$ with a $\mathrm{Cu}$ alloy, ${ }^{74}$ respectively. However, an obvious issue that arises upon multi-material processing is adequate powder recycling, i.e., post-processing separation of the mixed, unmelted powders. To provide for a more efficient alternative, the present study follows the approach of fabricating chemically tailored specimens by EBM from one initial powder feedstock. The material under investigation is a high-alloyed austenitic Cr-Mn-Ni steel (see "Materials and Methods" section for details). This particular alloy combines two advantages. Firstly, it contains Mn, which is the key element for tailoring mechanical properties, and at the same time is prone to vaporization 

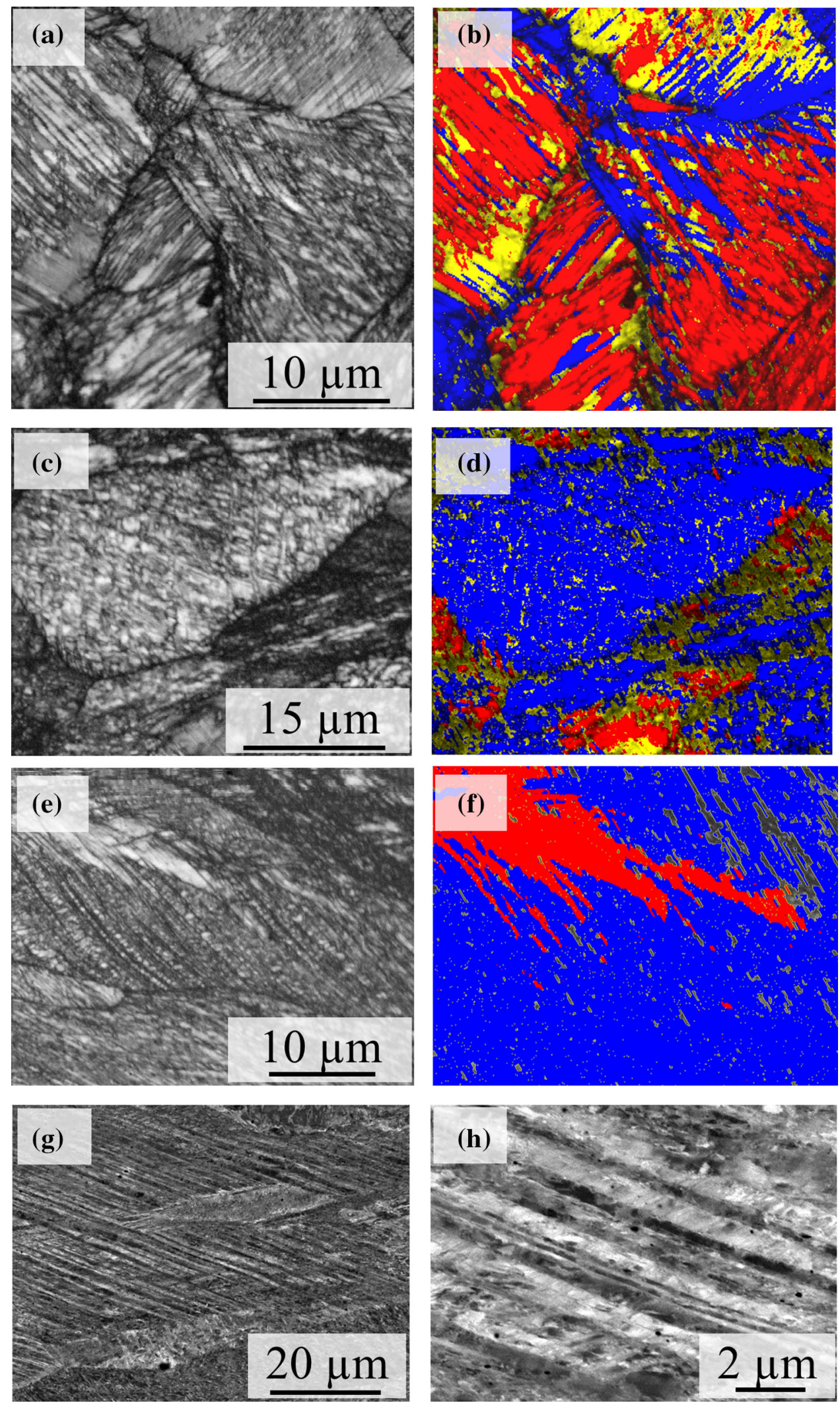

Fig. 3. (a), (c) and (e) EBSD IQ maps of specimens I, III and V upon tensile deformation to uniform elongation; (b), (d) and (f) phase maps corresponding to (a), (c) and (e), respectively; (g) BSE micrograph of specimen III, (h) magnified view of (g); (color coding: red fcc, blue bcc and yellow hexagonal). 

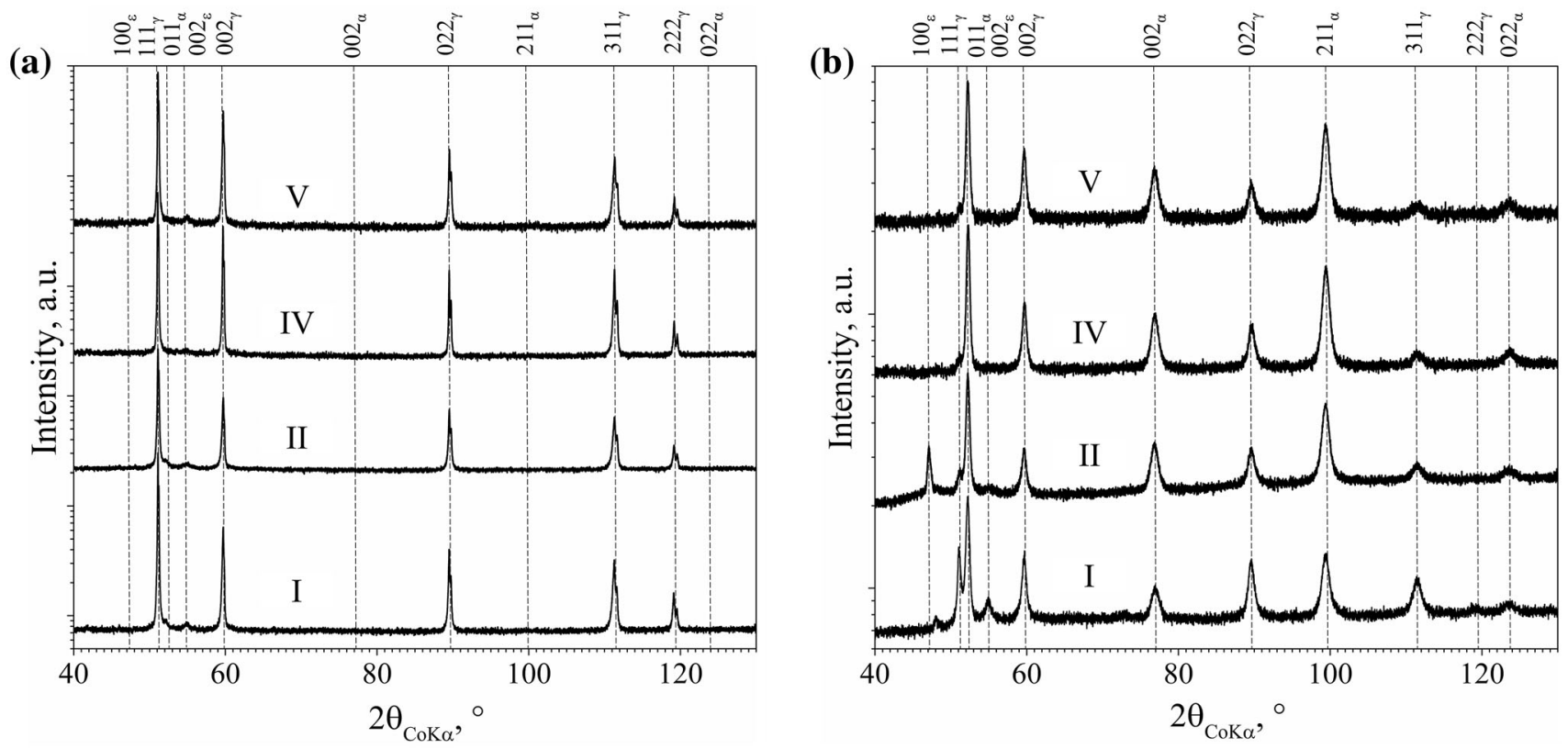

Fig. 4. XRD diffraction pattern for (a) as-built condition and (b) upon tensile deformation to uniform elongation of specimens of batches I, II, IV and $\mathrm{V}$.

during EBM processing (cf. Ref. 35, 46). Moreover, due to the EBM-inherent complex temperature history, i.e., repetitive re-melting and re-heating due to the consecutive layer-wise build-up of parts (cf. Ref. 35, 75-78), a homogeneous, fine-grained and weak-textured microstructure evolves independent of the process parameters and, thus, no mechanical anisotropy is observed.

The EBSD micrographs in Fig. 1 show the asbuilt microstructure of all the batches that were manufactured by EBM, applying the parameters defined in Table I. In agreement with further studies (cf. Ref. 35, 45), the material is consistently characterized by a relatively fine-grained microstructure, and no epitaxial growth of large columnar grains is seen despite a large variation of scan speed and eventually energy density, $E_{\mathrm{vol}}$. Representatively, the average grain size of batch I is denoted by $22 \mu \mathrm{m}$ and a weak crystallographic texture intensity of 1.84 MUD, as derived from EBSD data (cf. "Results" section). However, the various applied scan strategies have a significant impact on the Mn content of the specimens of all batches (cf. Table I). Thus, when using a high scan speed at constant beam current and hatch distance, i.e., a low energy density, $E_{\mathrm{vol}}$, as for batch I, the initial Mn content of the powder is only slightly reduced to 6.2 wt.\%. In contrast, with decreasing scan speed and increasing $E_{\mathrm{vol}}$, more Mn evaporates and the final $\mathrm{Mn}$ content can be diminished by about 50\% to approximately 3.3 wt. $\%$ in batch V. However, as can be deduced from batch III, there is not a linear correlation between $E_{\mathrm{vol}}$ and the $\mathrm{Mn}$ content. Furthermore, this value cannot be considered as an isolated value for the assessment of $\mathrm{Mn}$ loss: batch III is characterized by a nominal higher $E_{\text {vol }}$ than batch IV, however also a higher $\mathrm{Mn}$ content. Previous studies from Bertoli et al. and Mishurova et al. ${ }^{79,80}$ have already revealed that $E_{\text {vol }}$ is not necessarily a sufficient parameter for a comprehensive description of the complex EBM and L-PBF processes. In their studies, they demonstrated this exemplarily for residual stress and porosity formation. ${ }^{79,80}$ Instead, within the EBM process, the thermal influence of melting of adjacent scan tracks (in the case of meander-shaped scanning) within the same layer has to be additionally taken into account. Helmer et al. ${ }^{20}$ assessed process windows for the fabrication of IN 718 specimens under consideration of the so-called return time and the thermal diffusion length. The return time designates the time that the electron beam requires to re-melt or re-heat, respectively, an arbitrary point of a scan track during the irradiation of adjacent tracks. Thus, the longer the scan length and the slower the scan speed, the longer the time for heat conduction (corresponding to an increased thermal diffusion length) through previously consolidated material. This results in an intricate interplay between the nominal energy input per line or volume unit and the thermal history the material experiences. Eventually, the slower scan speed and increased hatch distance applied for batch III can result in lower maximum melt pool temperatures and, thus, in decreased Mn vaporization during processing. Further details can be found in recent literature, cf. Ref. 20, 35 .

Figure 2a displays the engineering stress versus engineering strain curves of all the examined batches. The different UTS and $\varepsilon_{\mathrm{t}}$ values are 
(a)

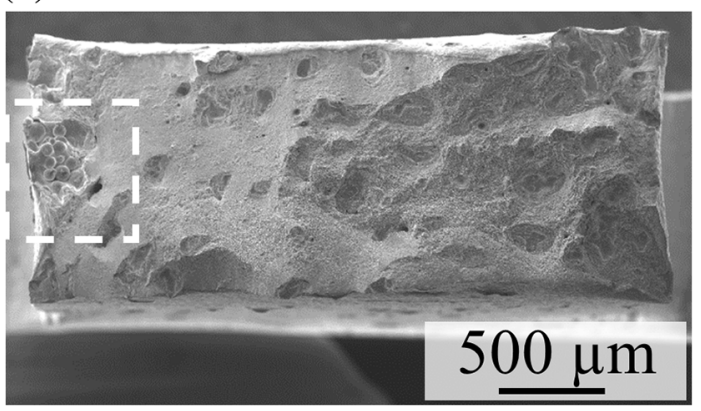

(c)

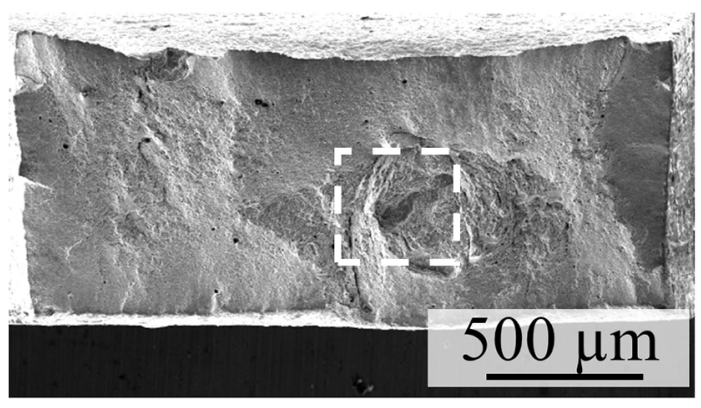

(e)

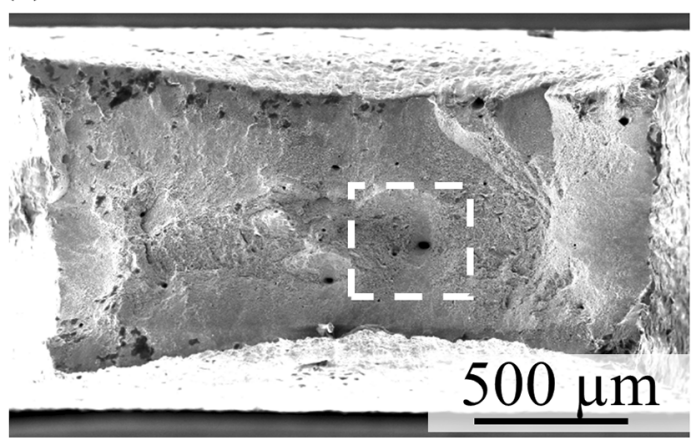

(b)

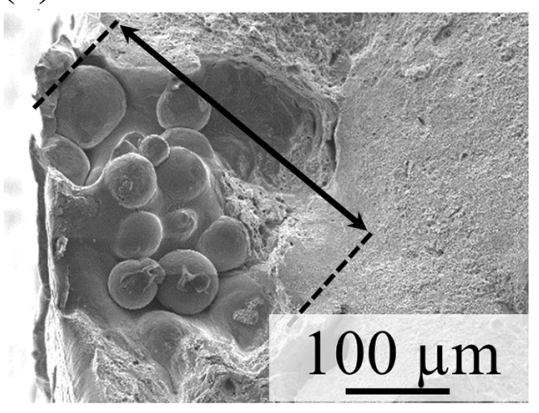

(d)

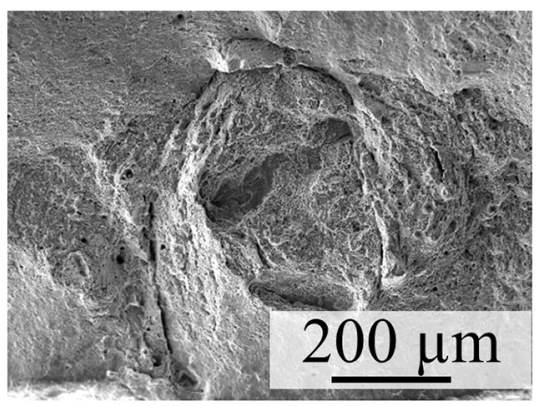

(f)

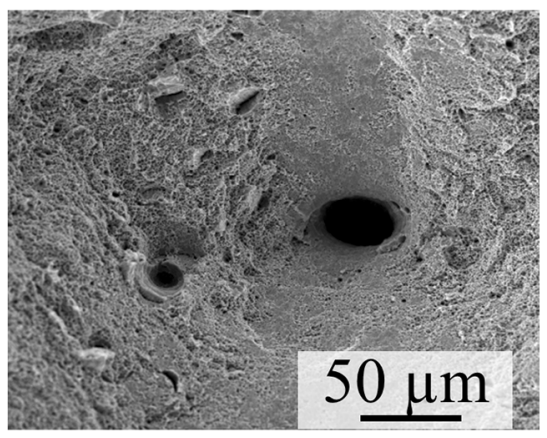

Fig. 5. Fracture surfaces of tensile specimens (a) I, (c) II and (e) V; (b), (d) and (f) show corresponding magnified views of the white dashed rectangles in (a), (c) and (e), respectively.

summarized in Table II. Differences are more pronounced when considering the true stress versus true strain and associated work-hardening curves in Fig. 2b. Batch I shows the lowest degree of hardening (mechanical behavior is superimposed by process-induced defects, as discussed below) followed by batch II. Batches III and IV, containing very similar contents of Mn, reveal similar strain-hardening, as expected from Fig. 2a. Batch V, however, shows most pronounced hardening, which is in good agreement with results from Wendler et al. ${ }^{48}$ who compared conventionally processed $14 \mathrm{Cr}-X \mathrm{Mn}-6 \mathrm{Ni}$ (wt.\%) specimens with varying $\mathrm{Mn}$ contents. They reported that a decreased Mn content leads to increased UTS and decreased total elongation. Both can be explained based on the influence of $\mathrm{Mn}$ on SFE, reduced austenite stability, and, eventually, the promotion of the martensitic phase transformation kinetics. In the present work, the specimens are characterized by almost similar SFE, as calculated by the empirical equation introduced by Dai et al. ${ }^{56}$ As summarized in Table II, the SFE values are only marginally influenced by the variation in $\mathrm{Mn}$ concentrations. However, they are all in a range, where the TRIP effect is the predominant deformation mechanism and deformation twinning is unlikely to occur. ${ }^{39}$ Additionally, in Table II, the $\mathrm{M}_{\mathrm{S}}$ temperatures, as calculated according to Jahn et al. ${ }^{57}$ are given. It can be seen that the differences in $M_{S}$ are approximately $35 \mathrm{~K}$ between batches $\mathrm{I}$ and $\mathrm{V}$, imposed by the differences in Mn content. This indicates significant differences in austenite stabilities, and is presumably the reason for the increase in $\alpha^{\prime}$ martensite fraction with decreasing $\mathrm{Mn}$ concentration upon tensile deformation.

The strengthening effect induced by phase transformation is based on the dynamic Hall-Petch effect, i.e., a continuous fragmentation and 
refinement of the microstructure through martensite domains eventually reducing the mean free dislocation path. ${ }^{41,42}$ During tensile deformation of specimens of batch $\mathrm{V}$ pronounced martensite formation occurs, hence, yielding the most pronounced strain hardening. Moreover, due to modified phase stabilities, upon deformation the microstructure consists mainly of $\alpha^{\prime}$ martensite, whereas, in batches with higher Mn content, relatively high $\varepsilon$ martensite fractions can be seen. This can be derived from Fig. 3 depicting EBSD IQ maps of deformed conditions (Fig. 3a, c and e) and corresponding phase maps (Fig. 3b, d and f) of specimens of batches I, II and V, respectively. From these representative EBSD measurements, although depicting statistically not relevant small sections only, it can be already deduced that, with decreasing $\mathrm{Mn}$ content, the bcc $\alpha^{\prime}$ fraction increases and domains that were indexed as hexagonal $\varepsilon$ are diminished. This trend is underlined by the statistically relevant XRD measurements shown in Fig. 4 for (a) as-built as well as (b) deformed conditions of batches I, II, IV and V. The specimens were deformed to uniform elongation and, thus, are in the same state as those studied by EBSD (Fig. 3). From quantitative analysis, it can be deduced that the as-built conditions consist of predominantly fcc $\gamma$ phase, whereas, upon deformation, large amounts of martensite prevail. Consistently, with decreasing Mn content, the amount of $\alpha^{\prime}$ martensite increases. In batches IV and V, no $\varepsilon$ martensite was detected upon tensile testing. Figure $3 \mathrm{~g}$ and $\mathrm{h}$ shows magnified views in SEM-BSE contrast mode of the microstructure of batch III upon tensile deformation. A high density of deformation bands is visible that forms by dislocation multiplication, motion of partial dislocations, and expansion of stacking faults, as usually observed for alloys with similarly low SFE values. The high density of structural defects seen is consistent with the pronounced XRD peak broadening in Fig. $4 \mathrm{~b}$; however, a thorough analysis of individual defects is clearly beyond the scope of the current study (for a comprehensive examination of the effect of intrinsic and extrinsic stacking fault configurations on diffraction characteristics of deformed austenitic Cr-Mn-Ni steels the reader is referred to Rafaja et al. ${ }^{36}$, Martin et al. ${ }^{81}$ and Ullrich et al. ${ }^{38}$ ). As formation characteristics of $\varepsilon$ martensite are linked to a particular arrangement of stacking faults on $\{111\}$ planes of the parent fcc $\gamma$ phase, hexagonal and fcc planes are virtually identical. Hence, narrowly spaced stacking faults could be identified as $\varepsilon$ martensite and do not contribute to the $\gamma$ diffraction signal intensity. $36,37,41,81$

Figure 5 shows the results of fractography for tensile specimens of batches I, II and V, with magnified views of dominant inhomogeneities. It can be seen that the scan strategy of batch I, i.e., applying the lowest $E_{\mathrm{vol}}$, results in very large $\mathrm{LoF}$ defects, and conglomerations of unmelted powder particles are present on the fracture surface. This is also reflected by the experimentally determined porosity of approximately $0.92 \%$ as noted in Table II. However, considering the size of the defects, the material still shows an outstanding mechanical behavior. This fact has already been reported. ${ }^{35}$ Nevertheless, the defect structure most likely superimposes the impact of $\mathrm{Mn}$ loss in terms of mechanical response and, thus, the impact of compositional variation is discussed exclusively in light of phase and microstructure evolution for this condition. In contrast, higher $E_{\mathrm{vol}}$ results in improved consolidation of the powder such that the remaining prevalent voids, especially in batches IV and V (cf. Fig. 5), are mainly gas pores stemming from gas entrapped in the powder particles as remnant from the atomization process (see previous section). These defects barely affect the mechanical behavior of the material under monotonic load, such that the chemical modification is predominantly responsible for the tensile behavior as well as the phase stabilities and final phase fractions. Batches II-V are also characterized by almost similar porosities as determined by Archimedes' principle.

A remaining challenge for future application of these alloys, their various derivates, and the general principle of compositional modification, is to guarantee the stable and robust processability as well as compositional and structural integrity throughout the AM component. Considering the fabrication of complex-shaped components by AM that are characterized by constantly varying scan lengths and cross-sections, spatial alterations of the beam settings could be necessary. Regarding the standard parameter themes provided by the machine manufacturer, this is often addressed by the utilization of automatic functions adjusting beam settings according to the geometry of the part. For example, the so-called "speed function" is a control scheme that aligns the beam speed to the actual current in order to maintain a homogeneous energy input throughout the exposed cross-section. ${ }^{27,82-85}$ In very sensitive materials, local process variations can have a significant impact on the overall performance of an AM component, e.g., as shown for a Ni-Ti shape memory alloy processed by L-PBF. ${ }^{86}$ However, as can be deduced from the applied range of $E_{\mathrm{vol}}$ and subsequent fractography, for the Cr-Mn-Ni austenitic steel, a relatively large process window allowing for the production of specimens is available. Minor differences in processing parameters do not result in a drastic and unfavorable change of mechanical properties. This can be seen by comparing batches III and IV that were melted using significantly different scan strategies. Even if the specimens are characterized by different Mn contents, they still exhibit almost equal deformation characteristics.

By focusing on the extreme, it has been demonstrated that chemical composition and properties can be tailored by proper process adjustment, e.g., when comparing batches II and V. Future work 
should focus on an expansion of the methodology and a maximization of the effects of element vaporization on the mechanical and thermodynamic properties. One approach could follow findings obtained for conventionally processed material published by Wendler et al. ${ }^{49}$ It was shown that an increased $\mathrm{Cr}$ fraction (or Cr-equivalent, $\mathrm{Cr}_{\mathrm{eq}}$ ) has an amplifying effect on the impact of $\mathrm{Mn}$. The results revealed that the austenite stabilizing effect of $\mathrm{Mn}$, and concomitantly the variation of martensite transformation temperatures (as quantified by the calculation of the Ni-equivalent, $\mathrm{Ni}_{\mathrm{eq}}$ ), is not constant but instead increases with increasing $\mathrm{Cr}_{\text {eq. }}{ }^{49}$ This in turn also indicates that a change in $\mathrm{Cr}_{\mathrm{eq}}$ would further enhance the effect of $\mathrm{Mn}$ evaporation during EBM processing on the resulting mechanical response of additively manufactured specimens. This aspect should be taken into consideration for the development of future alloys tailored for AM.

\section{CONCLUSION}

In the present study, austenitic high-alloyed $\mathrm{Cr}$ $\mathrm{Mn}-\mathrm{Ni}$ steel specimens were manufactured by EBM aiming at tailoring the chemical composition of final parts based on a single ingot powder. The results clearly reveal the possibility of modifying mechanical and thermodynamic properties by an adjustment of the scan strategy through controlling the vaporization of $\mathrm{Mn}$ during processing. From the obtained results, the following conclusions can be drawn:

(i) The Mn content can be significantly changed by a variation of the electron beam scan speed and, thus, the resulting energy density. Still, all specimens are characterized by a fine-grained almost isotropic microstructure.

(ii) Different Mn contents can result in distinct tensile strength and strain-hardening characteristics.

(iii) All specimens are predominantly austenitic in as-built condition. Combined EBSD and XRD examinations reveal a pronounced TRIP effect upon deformation as well as significant differences in microstructure evolution, depending on the chemical composition, associated deformation mechanisms and phase stabilities.

(iv) In summary, it has been shown that it is principally possible to produce parts with compositional and mechanical variations in a powder bed-based AM process from one homogeneous powder feedstock.

\section{ACKNOWLEDGEMENTS}

Open Access funding provided by Projekt DEAL. Financial support by Deutsche Forschungsgemeinschaft (DFG) within the Emmy-Noether-Project (Project Nos. 250216343; NI1327/7-3) and the col- laborative research center Sonderforschungsbereich 799 ("TRIP-Matrix-Composites") is gratefully acknowledged. The authors would like to thank Dr. Christian Schimpf (Institute for Materials Science, Technical University Freiberg) for XRD analysis.

\section{COMPETING INTERESTS}

The authors declare no competing financial interest.

\section{OPEN ACCESS}

This article is licensed under a Creative Commons Attribution 4.0 International License, which permits use, sharing, adaptation, distribution and reproduction in any medium or format, as long as you give appropriate credit to the original author(s) and the source, provide a link to the Creative Commons licence, and indicate if changes were made. The images or other third party material in this article are included in the article's Creative Commons licence, unless indicated otherwise in a credit line to the material. If material is not included in the article's Creative Commons licence and your intended use is not permitted by statutory regulation or exceeds the permitted use, you will need to obtain permission directly from the copyright holder. To view a copy of this licence, visit http://creativecommons.org/licenses/by/4.0/.

\section{REFERENCES}

1. W.E. Frazier, J. Mater. Eng. Perform. 23, 191 (2014).

2. J.J. Lewandowski and M. Seifi, Annu. Rev. Mater. Res. 46, 151 (2016)

3. L.E. Murr, S.M. Gaytan, D.A. Ramirez, E. Martinez, J. Hernandez, K.N. Amato, P.W. Shindo, F.R. Medina, and R.B. Wicker, J. Mater. Sci. Technol. 28, 1 (2012).

4. D. Herzog, V. Seyda, E. Wycisk, and C. Emmelmann, Acta Mater. 117, 371 (2016).

5. K.S. Chan, M. Koike, R.L. Mason, and T. Okabe, Metall. Mater. Trans. A 44, 1010 (2013).

6. N. Hrabe and T. Quinn, Mater. Sci. Eng., A 573, 264 (2013).

7. K.P. Karunakaran, A. Bernard, S. Suryakumar, L. Dembinski, and G. Taillandier, Rapid Prototyp. J. 18, 264 (2012).

8. V. Petrovic, J. Vicente Haro Gonzalez, O. Jordá Ferrando, J. Delgado Gordillo, J. Ramón Blasco Puchades, and L. Portolés Griñan, Int. J. Prod. Res. 49, 1061 (2011).

9. M. Schmidt, M. Merklein, D. Bourell, D. Dimitrov, T. Hausotte, K. Wegener, L. Overmeyer, F. Vollertsen, and G.N. Levy, CIRP Ann. 66, 561 (2017).

10. M. Grasso and B.M. Colosimo, Meas. Sci. Technol. 28, 044005 (2017).

11. J. Günther, D. Krewerth, T. Lippmann, S. Leuders, T. Tröster, A. Weidner, H. Biermann, and T. Niendorf, Int. J. Fatigue 94, 236 (2017).

12. S. Leuders, M. Thöne, A. Riemer, T. Niendorf, T. Tröster, H.A. Richard, and H.J. Maier, Int. J. Fatigue 48, 300 (2013).

13. G. Kasperovich and J. Hausmann, J. Mater. Process. Technol. 220, 202 (2015).

14. D. Greitemeier, F. Palm, F. Syassen, and T. Melz, Int. J. Fatigue 94, 211 (2017).

15. M. Tang, P.C. Pistorius, and J.L. Beuth, Addit. Manuf. 14, 39 (2017).

16. A. Basak and S. Das, Annu. Rev. Mater. Res. 46, 125 (2016).

17. R.R. Dehoff, M.M. Kirka, W.J. Sames, H. Bilheux, A.S. Tremsin, L.E. Lowe, and S.S. Babu, Mater. Sci. Technol. 31, 931 (2015). 
18. M.M. Kirka, Y. Lee, D.A. Greeley, A. Okello, M.J. Goin, M.T. Pearce, and R.R. Dehoff, JOM 69, 5231 (2017).

19. H. Helmer, A. Bauereiß, R.F. Singer, and C. Körner, Mater. Sci. Eng., A 668, 180 (2016).

20. H.E. Helmer, C. Körner, and R.F. Singer, J. Mater. Res. 29, 1987 (2014).

21. L.A. Al-Juboori, T. Niendorf, and F. Brenne, Metall. Mater. Trans. B 49B, 2969 (2018).

22. F. Brenne, A. Taube, M. Pröbstle, S. Neumeier, D. Schwarze, M. Schaper, and T. Niendorf, Prog. Addit. Manuf. 1, 141 (2016).

23. L. Thijs, K. Kempen, J.P. Kruth, and J. Van Humbeeck, Acta Mater. 61, 1809 (2013).

24. A.A. Antonysamy, J. Meyer, and P.B. Prangnell, Mater. Charact. 84, 153 (2013).

25. A.A. Antonysamy, P.B. Prangnell, and J. Meyer, Mater. Sci. Forum 706-709, 205 (2012).

26. A. Riemer, S. Leuders, M. Thöne, H.A. Richard, T. Tröster, and T. Niendorf, Eng. Fract. Mech. 120, 15 (2014).

27. C. Wang, X. Tan, E. Liu, and S.B. Tor, Mater. Des. 147, 157 (2018).

28. D.F. Nelson, eds., Second and Higher Order Elastic Constants (Berlin/Heidelberg: Springer, 1992).

29. C. Ullrich, R. Eckner, L. Krüger, S. Martin, V. Klemm, and D. Rafaja, Mater. Sci. Eng., A 649, 390 (2016).

30. D. Geissler, J. Freudenberger, A. Kauffmann, M. Krautz, H. Klauss, A. Voss, J. Eickemeyer, and L. Schultz, Acta Mater. 59, 7711 (2011).

31. E. Liverani, S. Toschi, L. Ceschini, and A. Fortunato, J. Mater. Process. Technol. 249, 255 (2017).

32. R. Casati, J. Lemke, and M. Vedani, J. Mater. Sci. Technol. 32,738 (2016).

33. M.E. Aydinöz, F. Brenne, M. Schaper, C. Schaak, W. Tillmann, J. Nellesen, and T. Niendorf, Mater. Sci. Eng., A 669, 246 (2016)

34. M.M. Kirka, D.A. Greeley, C. Hawkins, and R.R. Dehoff, Int. J. Fatigue 105, 235 (2017).

35. J. Günther, F. Brenne, M. Droste, M. Wendler, O. Volkova, H. Biermann, and T. Niendorf, Sci. Rep. 8, 1298 (2018).

36. D. Rafaja, C. Krbetschek, D. Borisova, G. Schreiber, and V. Klemm, Thin Solid Films 530, 105 (2013).

37. D. Rafaja, C. Krbetschek, C. Ullrich, and S. Martin, J. Appl. Crystallogr. 47, 936 (2014).

38. C. Ullrich, S. Martin, C. Schimpf, A. Stark, N. Schell, and D. Rafaja, Adv. Eng. Mater. 21, 1801101 (2019).

39. S. Martin, S. Wolf, U. Martin, L. Krüger, and D. Rafaja, Metall. Mater. Trans. A 47, 49 (2016).

40. E.I. Galindo-Nava and P.E.J. Rivera-Díaz-del-Castillo, Acta Mater. 128, 120 (2017).

41. A. Weidner and H. Biermann, JOM 67, 1729 (2015).

42. S. Martin, S. Wolf, S. Decker, L. Krüger, and U. Martin, Steel Res. Int. 86, 1187 (2015).

43. A. Kovalev, A. Jahn, A. Weiß, S. Wolf, and P.R. Scheller, Steel Res. Int. 83, 576 (2012)

44. A. Weidner, S. Martin, V. Klemm, U. Martin, and H. Biermann, Scr. Mater. 64, 513 (2011).

45. M. Droste, J. Günther, D. Kotzem, F. Walther, T. Niendorf, and H. Biermann, Int. J. Fatigue 114, 262 (2018).

46. T. Dubberstein, M. Hötzel, R. Hagemann, P. Heller, and P.R. Scheller, Steel Res. Int. 82, 1122 (2011).

47. A. Salak and M. Selecká, Manganese in Powder Metallurgy Steels (Cambridge: International Science, 2012).

48. M. Wendler, A. Weiß, L. Krüger, J. Mola, A. Franke, A. Kovalev, and S. Wolf, Adv. Eng. Mater. 15, 558 (2013).

49. M. Wendler, J. Mola, L. Krüger, and A. Weiß, Steel Res. Int. 85, 803 (2014).

50. C.A. Brice, W.A. Tayon, J.A. Newman, M.V. Kral, C. Bishop, and A. Sokolova, Mater. Charact. 143, 50 (2018).

51. T. Mukherjee, J.S. Zuback, A. De, and T. DebRoy, Sci. Rep. 6, 19717 (2016).

52. A. Klassen, T. Scharowsky, and C. Körner, J. Phys. Appl. Phys. 47, 275303 (2014).
53. A. Klassen, V.E. Forster, and C. Körner, Model. Simul. Mater. Sci. Eng. 25, 025003 (2017).

54. F. Hengsbach, P. Koppa, M.J. Holzweissig, M.E. Aydinöz, A. Taube, K.-P. Hoyer, O. Starykov, B. Tonn, T. Niendorf, T. Tröster, and M. Schaper, Prog. Addit. Manuf. 3, 221 (2018).

55. M. Linderov, C. Segel, A. Weidner, H. Biermann, and A. Vinogradov, Mater. Sci. Eng., A 597, 183 (2014)

56. Q.X. Dai, A.D. Wang, X.N. Cheng, and X.M. Luo, Chin. Phys. 11, 596 (2002).

57. A. Jahn, A. Kovalev, A. Weiß, and P.R. Scheller, Steel Res. Int. 82, 1108 (2011)

58. S. Tammas-Williams, H. Zhao, F. Léonard, F. Derguti, I. Todd, and P.B. Prangnell, Mater. Charact. 102, 47 (2015).

59. R. Cunningham, S.P. Narra, C. Montgomery, J. Beuth, and A.D. Rollett, JOM 69, 479 (2017)

60. R. Cunningham, S.P. Narra, T. Ozturk, J. Beuth, and A.D. Rollett, JOM 68, 765 (2016)

61. N. Ikeo, T. Ishimoto, and T. Nakano, J. Alloys Compd. 639, 336 (2015).

62. X. Li, C. Wang, W. Zhang, and Y. Li, Mater. Lett. 63, 403 (2009).

63. D. Mahmoud and M. Elbestawi, J. Manuf. Mater. Process. 1, 13 (2017)

64. S. Tammas-Williams and I. Todd, Scr. Mater. 135, 105 (2017)

65. T. Niendorf, S. Leuders, A. Riemer, F. Brenne, T. Tröster, H.A. Richard, and D. Schwarze, Adv. Eng. Mater. 16, 857 (2014).

66. T. Niendorf, S. Leuders, A. Riemer, H.A. Richard, T. Tröster, and D. Schwarze, Metall. Mater. Trans. B 44, 794 (2013).

67. R.R. Dehoff, M.M. Kirka, F.A. List, K.A. Unocic, and W.J. Sames, Mater. Sci. Technol. 31, 939 (2015).

68. C.H. Zhang, H. Zhang, C.L. Wu, S. Zhang, Z.L. Sun, and S.Y. Dong, Vacuum 141, 181 (2017).

69. Q. Wang, S. Zhang, C. Zhang, C. Wu, J. Wang, J. Chen, and Z. Sun, Vacuum 141, 68 (2017).

70. Q. Wang, S. Zhang, C.H. Zhang, C.L. Wu, L. Ren, J.Q. Wang, and J. Chen, Acta Metall. Sin. Engl. Lett. 31, 19 (2018).

71. T. Mukherjee, J.S. Zuback, W. Zhang, and T. DebRoy, Comput. Mater. Sci. 143, 325 (2018).

72. W. Li, L. Yan, X. Chen, J. Zhang, X. Zhang, and F. Liou, J. Mater. Process. Technol. 255, 96 (2018).

73. F. Kies, P. Köhnen, M.B. Wilms, F. Brasche, K.G. Pradeep, A. Schwedt, S. Richter, A. Weisheit, J.H. Schleifenbaum, and C. Haase, Mater. Des. 160, 1250 (2018).

74. Z.H. Liu, D.Q. Zhang, S.L. Sing, C.K. Chua, and L.E. Loh, Mater. Charact. 94, 116 (2014).

75. Y. Liu, J. Zhang, and Z. Pang, Opt. Laser Technol. 98, 23 (2018).

76. P. Krakhmalev, I. Yadroitsava, G. Fredriksson, and I. Yadroitsev, Mater. Des. 87, 380 (2015).

77. M.M. Kirka, P. Nandwana, Y. Lee, and R.R. Dehoff, Scr. Mater. 135, 130 (2017).

78. V. Manvatkar, A. De, and T. DebRoy, Mater. Sci. Technol. 31, 924 (2015).

79. U. Scipioni Bertoli, A.J. Wolfer, M.J. Matthews, J.P.R. Delplanque, and J.M. Schoenung, Mater. Des. 113, 331 (2017).

80. T. Mishurova, K. Artzt, J. Haubrich, G. Requena, and G. Bruno, Addit. Manuf. 25, 325 (2019).

81. S. Martin, C. Ullrich, D. Simek, U. Martin, and D. Rafaja, J. Appl. Crystallogr. 44, 779 (2011).

82. S.S. Al-Bermani, An Investigation into Microstructure and Microstructural Control of Additive Layer Manufactured Ti$6 \mathrm{Al}-4 \mathrm{~V}$ by Electron Beam Melting (Sheffield: University of Sheffield, 2011).

83. W.J. Sames, F.A. List, S. Pannala, R.R. Dehoff, and S.S. Babu, Int. Mater. Rev. 61, 315 (2016).

84. W. Sames, Additive Manufacturing of Inconel 718 Using Electron Beam Melting: Processing, Post-Processing, \& Mechanical Properties (Texas: A\&M University, 2015).

85. X. Wang, X. Gong, and K. Chou, Procedia Manuf. 1, 287 (2015). 
86. B.E. Franco, J. Ma, B. Loveall, G.A. Tapia, K. Karayagiz, J. Liu, A. Elwany, R. Arroyave, and I. Karaman, Sci. Rep. 7, 3604 (2017).
Publisher's Note Springer Nature remains neutral with regard to jurisdictional claims in published maps and institutional affiliations. 